\title{
Demographic Profile of Older Adults Using Wheeled Mobility Devices
}

\author{
Amol M. Karmarkar, ${ }^{1}$ Brad E. Dicianno, ${ }^{2,3}$ Rosemarie Cooper, ${ }^{2,4}$ Diane M. Collins, ${ }^{4}$ \\ Judith T. Matthews, ${ }^{5}$ Alicia Koontz, ${ }^{2,4}$ Emily E. Teodorski, ${ }^{2,4}$ and Rory A. Cooper ${ }^{2,4}$ \\ ${ }^{1}$ Division of Rehabilitation Sciences, The University of Texas Medical Branch, Galveston, TX 77555, USA \\ ${ }^{2}$ Human Engineering Research Laboratories, VA Pittsburgh Healthcare System, 7180 Highland Drive, Bldg. 4, 2nd Floor, \\ 151R1-HD, Pittsburgh, PA 15206, USA \\ ${ }^{3}$ Department of Physical Medicine and Rehabilitation, University of Pittsburgh, Pittsburgh, PA 15213, USA \\ ${ }^{4}$ Department of Rehabilitation Science and Technology, University of Pittsburgh, Pittsburgh, PA 15260, USA \\ ${ }^{5}$ Department of Health and Community Systems, University of Pittsburgh, Pittsburgh, PA 15261, USA
}

Correspondence should be addressed to Rory A. Cooper, rcooper@pitt.edu

Received 3 March 2011; Accepted 31 March 2011

Academic Editor: Wojtek Chodzko-Zajko

Copyright (C) 2011 Amol M. Karmarkar et al. This is an open access article distributed under the Creative Commons Attribution License, which permits unrestricted use, distribution, and reproduction in any medium, provided the original work is properly cited.

\begin{abstract}
The purpose of this study was to determine whether the use of wheeled mobility devices differed with respect to age, gender, residential setting, and health-related factors among older adults. A total of 723 adults ageing 60 and older are representing three cohorts, from nursing homes, the Center for Assistive Technology, and the wheelchair registry from the Human Engineering Research Laboratories. Wheeled mobility devices were classified into three main groups: manual wheelchairs, power wheelchairs, and scooters. Our results found factors including age, gender, diagnosis, and living settings to be associated with differences in use of manual versus powered mobility devices. Differences in use were also noted for subtypes of manual (depot, standard, and customized) and powered (scooter, standard, and customized) mobility devices, on demographic, living arrangements, and healthrelated factors. Consideration of demographic, health-related, and environmental factors during the prescription process may help clinicians identify the most appropriate mobility device for the user.
\end{abstract}

\section{Background}

Exponential growth in the number of older adults $(>65$ years) worldwide is expected to occur over the next half century. In the US alone, the elderly population was estimated to be 40 million in 2010 and is projected to climb to approximately 87 million by 2050 [1]. Assistive technology (AT) decreases the residual difficulties experienced by older adults as they perform daily activities, thereby reducing their reliance on others and, in turn, lowering the probability of placement in long-term care facilities. About $5 \%$ of all older individuals in the US are currently living in institutional settings. This increase in life expectancy has resulted in a growing need by this population for human assistance, technology support, or both for performance of daily activities [2-4].
Wheeled mobility devices (WhMDs), which include manual wheelchairs, power wheelchairs, and scooters, are assistive technologies commonly used by older adults. These devices may be customized and may increase independence in activities of daily living and reduce the need for human help [5]. However, a mismatch between the needs of the end users and the types of devices prescribed may result in an increased need for personal assistance or may result in abandonment of these devices [6].

In the US, an estimated 1 million WhMD users are aged 65 and older, the majority of whom use manual wheelchairs (MWC) [7]. Several factors such as fear of falling during walking; desire for faster and more efficient mobility; physical limitations such as muscle weakness, impaired balance, pain, or visual impairment that impede walking ability have been associated with the use of WhMDs by ambulatory 
older adults in skilled nursing facilities [8]. A cross-sectional study of community dwelling, older Canadians revealed gender (men > women), level of functional limitation (greater functional limitation $>$ lesser functional limitation), and living arrangement (alone > living with someone) are indicators for increased WhMDs use [9].

The utilization of WhMDs among older adults differs by living setting. Though clinicians may view use of WhMDs as a means of improving independent mobility, wheelchairs are often provided for nursing home residents to meet their positioning needs or merely for improving transportation efficiency [10]. In one study, residents of a nursing home reported that the use of wheelchairs improved their level of independence in functional mobility, their efficiency and safety during mobility [8].

In general, a wide gap exists between the perspectives of clinicians and those of the end users, with respect to the use of wheelchairs. The utilization of a prescribed WhMD depends on several factors including: demographic characteristics (e.g., age, gender), health (e.g., physical impairments, functional limitations, comorbid conditions), characteristics of the WhMD (e.g., condition, type, size), environmental facilitators, and barriers (e.g., accessible living situation), and whether the device is prescribed by a specialist in AT or a nonspecialist [11-13]. Demographics and healthrelated characteristics of the end users are significant determinants of the extent to which they use their wheelchairs.

Older adults frequently report having difficulty using their wheelchairs. Ganesh and colleagues found that $61 \%$ of their sample of older adults reported difficulty with manual wheelchair propulsion, indicating that mobility devices provided for older adults may not be meeting their needs [14]. The study suggested that factors other than user characteristics, such as environmental barriers and professional intervention, may be determinants of wheelchair use.

Several descriptive and exploratory studies have revealed age and racial disparities in the provision of WhMDs to individuals with mobility impairments. Hunt and colleagues reported that low socioeconomic status was a key determinant of use of standard manual wheelchairs instead of customizable (or rehab) wheelchairs among individuals with spinal cord injury (SCI), [14]. Older ages of the end users were related to their use of standard power wheelchairs rather than a customized power wheelchairs [15]. A study by Hubbard and colleagues reported that racial origin of the end user-white versus nonwhite-determined the type of power wheelchair used, customized versus standard [16], whereas Resnik and Allen found that age explained differences in mobility device use between white and nonwhite older adults [17]. Cornman and Freedman suggested that racial and ethnic disparities in the use of wheelchairs and walkers could be explained by the differences in human and environmental factors [18]. Yet, research is lacking regarding the extent of use of WhMD, specifically among older adults. The studies that exist for this population emphasize racial and ethnic disparities, rather than other factors that are clinically important for the prescription and use of the WhMD.
The objectives of the current retrospective exploratory study were to determine the types of WhMD (MWC, PWC, and scooters) used by older adults who reside in nursing homes and community settings, and to identify the demographic and health-related factors associated with each type of WhMD being used.

\section{Methods}

2.1. Study Design. This study involved secondary analysis of data compiled from prior investigations of nursing home residents, medical record review of clients of the Center for Assistive Technology (CAT) at the University of Pittsburgh Medical Center (UPMC), and the wheelchair research registry of the Human Engineering Research Laboratories (HERL) of the VA Pittsburgh Healthcare System (Figure 1).

2.2. Sample. Data were collected from three cohorts (nursing home residents, CAT clients, and HERL registry participants) of individuals who were aged 60 years and older and used a wheeled mobility device for which details regarding the make, model, and other features of their WhMD were available. Individuals, whose wheelchairs were used as positioning devices, had power assist (power add on) capabilities or were temporary (e.g., rental) and excluded from the analyses. The first cohort consisted of 109 residents of five nursing homes (two VA-affiliated and three privately operated) in southwestern Pennsylvania who had been provided with a WhMD as part of their long-term care plan. The 334 clients who had received a new wheeled mobility device through the CAT during calendar years 2007 and 2008 formed the second cohort. The HERL wheelchair research registry (see Appendix) included persons from across the US and contributed data from 280 registrants.

All of the above individual studies received Institutional Review Board (IRB) approvals prior to their respective data collection. The study involving participants living in nursing home was approved by the VA IRB and by the Pennsylvania Department of Health. The study conducted on the data related to patients receiving WhMDs from the CAT was approved as an exempt protocol by the University of Pittsburgh IRB. The HERL registry was approved by the VA IRB.

2.3. Classification of Wheeled Mobility Devices. WhMDs were classified into three main groups (manual wheelchair, power wheelchair, or scooter) on the basis of their make, model, and type. Subtypes of manual wheelchairs (depot versus standard versus customizable - rehab) and power wheelchairs (standard versus customizable) were further classified according to the Health Care Common Procedure Coding System (HCPCS) of the Centers for Medicare and Medicaid Services (CMS). Additional classification criteria for manual wheelchairs were the weight of the wheelchair (i.e., depot, lightweight, and ultra light weight) and adjustability features (e.g., axle positions, seat height, seat dump). Manual wheelchairs were classified as "depot style" if the particular 


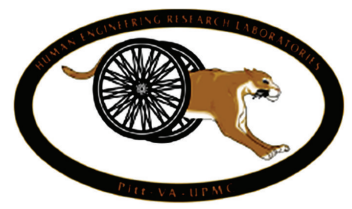

\section{Wheelchair Users \\ Registry}

Questionnaire

Date

First Name

Last Name

Street Address

City

State

Zip Code

Home Phone

Alternate Phone

E-mail Address

I prefer to be contacted by: $\quad \square$ No preference

Telephone Call

$\square$ Mail

E-mail

How did you hear about us?

Newsletter

Internet

Brochure

Games

Expo

Other

Would you like to receive the HERL newsletter? (typically sent 2-3 times per year)

$\square$ Yes

No

Date of Birth

Gender $\square$ Male $\square$ Female

Are you a veteran? $\square$ Yes $\square$ No

Race/Ethnicity $\square$ Black or African American $\quad \square$ Asian $\quad \square$ White or Caucasian $\square$ Hispanic or Latino

American Indian or Alaskan Native $\quad \square$ Native Hawaiian or other Pacific Islander $\quad \square$ Two or more races

Do you use a computer? $\square$ Yes $\square$ No

Do you use adaptive computer equipment or software? $\square$ Yes $\square$ No

Do you use a communication device? (speech output device) $\quad \square$ Yes $\square$ No

Do you (or have you ever) build and use assistive technology of your own design? $\square$ Yes $\square$ No

Do you (or have you ever) modified commercially

available assistive technology to better suit your needs? $\square$ Yes $\square$ No

If yes, what types of assistive technology have you modified or designed?

$\square$ Wheelchair related (accessories, etc)

$\square$ Automobile related (hand controls, etc)

$\square$ Home

Personal Care (grooming, eating)

Work place (tools, computer access)

Other

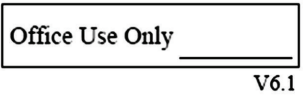

(a)

Figure 1: Continued. 
Injury or Diagnosis (please check all that apply)

Date of Injury or Diagnosis

Spinal Cord Injury: $\quad \square$ Paraplegia $\quad \square \quad$ Tetraplegia/Quadriplegia

Level of Injury (e.g. T2, C4-6)

Is your injury: $\square$ Complete $\quad \square$ Incomplete
Upper Extremity Amputation
Spina Bifida
Traumatic Brain Injury
Lower Extremity Amputation
Muscular Dystrophy
Stroke
Osteo/Rheumatoid Arthritis
Cerebral Palsy
Other
Post Polio Syndrome
Multiple Sclerosis

What date did you start using a wheelchair or scooter?

What type of chair do you currently use as your primary means of mobility? (please choose one)

Make (Brand) of your Primary Wheelchair
Manual Wheelchair

Power Wheelchair

Action/Invacare

Kuschall

Permobil

Sunrise/Quickie

Other

\section{Model of your Primary Wheelchair}

(if unsure, please look for a label on your wheelchair)

If you use a power wheelchair, does your wheelchair have any of the following... (please check all that apply)
Tilt-in-Space
Elevating legrests
Backrest Recline
Seat Elevator

\section{When using transportation, do you... \\ Use your wheelchair as a seat}

What is your primary means of transportation? (please choose one)

Non-modified private vehicle

Public transportation (bus, metro, train, etc)
Modified private vehicle (hand controls, lifts, ramps, etc)

Paratransit service (van, demand response) $\quad \square$ Other

Office Use Only

(b) 
model/type listed for weighting more than $36 \mathrm{lbs}$ and nonadjustable. Standard manual wheelchairs were classified as those weigh less than $36 \mathrm{lbs}$, and provide some adjustability in axle and/or seat and back height. Customized manual wheelchairs were defined as those weigh less than $30 \mathrm{lbs}$ and provide complete adjustability [15]. Power wheelchairs were categorized as standard or customizable based on criteria that included programmability of controls (determined by the make and model), seating base, customized features (e.g., tilt, recline, seat elevator), type of wheelchair motor (standard versus heavy duty), and weight capacity $(<250 \mathrm{lbs}$ and $>250 \mathrm{lbs}$ ). This coding system for power wheelchairs was used in prior studies $[15,16,19,20]$ and resulted in the following groupings for our secondary analysis:

Group 1: intended for light use, no power options and seating systems (wheelchair product codes: K0813-K0816);

Group 2: consumer rehabilitation; no power, single power, or multiple power options; intended for individuals with limited use throughout the day (wheelchair product codes: K0820-K0843);

Group 3: complex rehabilitation; no power, single power or multiple power options; intended for all day use (wheelchair product codes: K0848-K0864);

Group 4: high activity use, heavy duty (wheelchair product codes: K0868-K0886).

2.4. Data Analyses. Descriptive statistics were computed for the entire data set. The data were then classified into five distinct tiers. Individuals using manual wheelchairs versus those using powered mobility devices (power wheel-chairs and scooters) comprised the Tier 1 Classification (see Figure 2). For the Tier 2 Classification, the manual wheelchair group was further classified into those using depot manual wheelchairs and those using other types of manual wheelchairs (standard and customizable manual wheelchairs). The latter group was further classified (Tier 3) into those using standard manual wheelchairs and those using customizable manual wheelchairs. Tier 4 classification involved the categorization of individuals based upon two subtypes of powered mobility devices: scooters and power wheelchairs. The group of power wheelchair users was further classified for Tier 5 into those using standard power wheelchairs and those using customizable power wheelchairs.

At all Tiers, group differences in age, measured as a continuous variable were assessed using an independent ttest. For categorical variables including gender, diagnosis, and residential setting, the association with type of WhMDs was determined using the chi-square test for independent groups (Fisher exact test was conducted when cells had fewer than 5 observations). All statistical analyses were computed using SPSS 16.0. Significance was set at $P<.05$, and $P$ value greater than .05 but less than .10 were considered as evidence of a trend.

\section{Results}

3.1. Demographics. Our sample of 723 older adults included 401 males (56\%) and 322 females (44\%) whose most common primary medical diagnoses were neurological disorders $(n=285)$, spinal cord conditions $(n=173)$, and orthopedic conditions $(n=140)$. Among the neurological conditions, cerebral vascular accidents including hemiplegia and hemiparesis $(n=86)$ were most prevalent, followed by multiple sclerosis $(n=73)$ and movement disorders $(n=35)$. Spinal cord injury was the most prevalent diagnosis ( $n=144)$ among those with spinal cord conditions. The most common orthopedic conditions were arthritis-related $(n=82)$ and amputations $(n=40)$. The vast majority of older adults lived at home $(n=576)$, with 147 residing in nursing homes or independent living centers (see Table 1).

Tier 1: Factors Associated with Use of Manual versus Powered Wheeled Mobility Devices. Individuals who used manual wheelchairs were older $(t=-3, P=.003)$ and more likely to be male $\left(\chi^{2}=37, P<.001\right)$ have spinal cord conditions $\left(\chi^{2}=22.4, P<.001\right)$ and did not live at home $\left(\chi^{2}=102.2\right.$, $P<.001)$, compared with those who used powered mobility devices (Table 2).

Tier 2: Factors Associated with Use of Depot versus Other Manual Wheelchairs. Depot style manual wheelchairs were more commonly used by older individuals $(t=2.6, P=.009)$, women $\left(\chi^{2}=6.1, P=.01\right)$, and those with cardiovascular and pulmonary diagnoses $\left(\chi^{2}=8.5, P=.05\right)$ than other types of manual wheelchairs. We also found a positive trend for living setting $\left(\chi^{2}=3.4, P=.07\right)$, with those living at home more often using lighter weight, adjustable manual wheelchairs than depot style wheelchairs (Table 3).

Tier 3: Factors Associated with Use of Standard versus Customized Manual Wheelchairs. Standard manual wheelchairs rather than lighter weight, customized manual wheelchairs were more common among individuals who were older $(t=$ 9, $P<0.001)$, female $\left(\chi^{2}=8.8, P=.003\right)$, had neurological or cardiovascular and pulmonary conditions $\left(\chi^{2}=66.7\right.$, $P<.001)$, and did not live at home $\left(\chi^{2}=97.2, P<.001\right)$, (Table 4).

Tier 4: Factors Associated with Use of Scooters versus Power Wheelchairs. Individuals with a primary diagnosis of cardiovascular and pulmonary conditions $\left(\chi^{2}=28.6, P<.001\right)$ and those living at home $\left(\chi^{2}=4, P=.04\right)$ were more likely to use scooters rather than power wheelchairs. No differences in age $(t=0.02, P=.98)$ or gender $\left(\chi^{2}=0.01, P=.92\right)$ were observed between scooter and power wheelchair users (Table 5).

Tier 5: Factors Associated with Use of Standard versus Customized Power Wheelchair. Individuals who were older $(t=$ $3.5, P<.001)$, female $\left(\chi^{2}=16.2, P<.001\right)$ and had a primary diagnosis of orthopedic or cardiovascular and pulmonary conditions $\left(\chi^{2}=52.7, P<.001\right)$ were more likely 


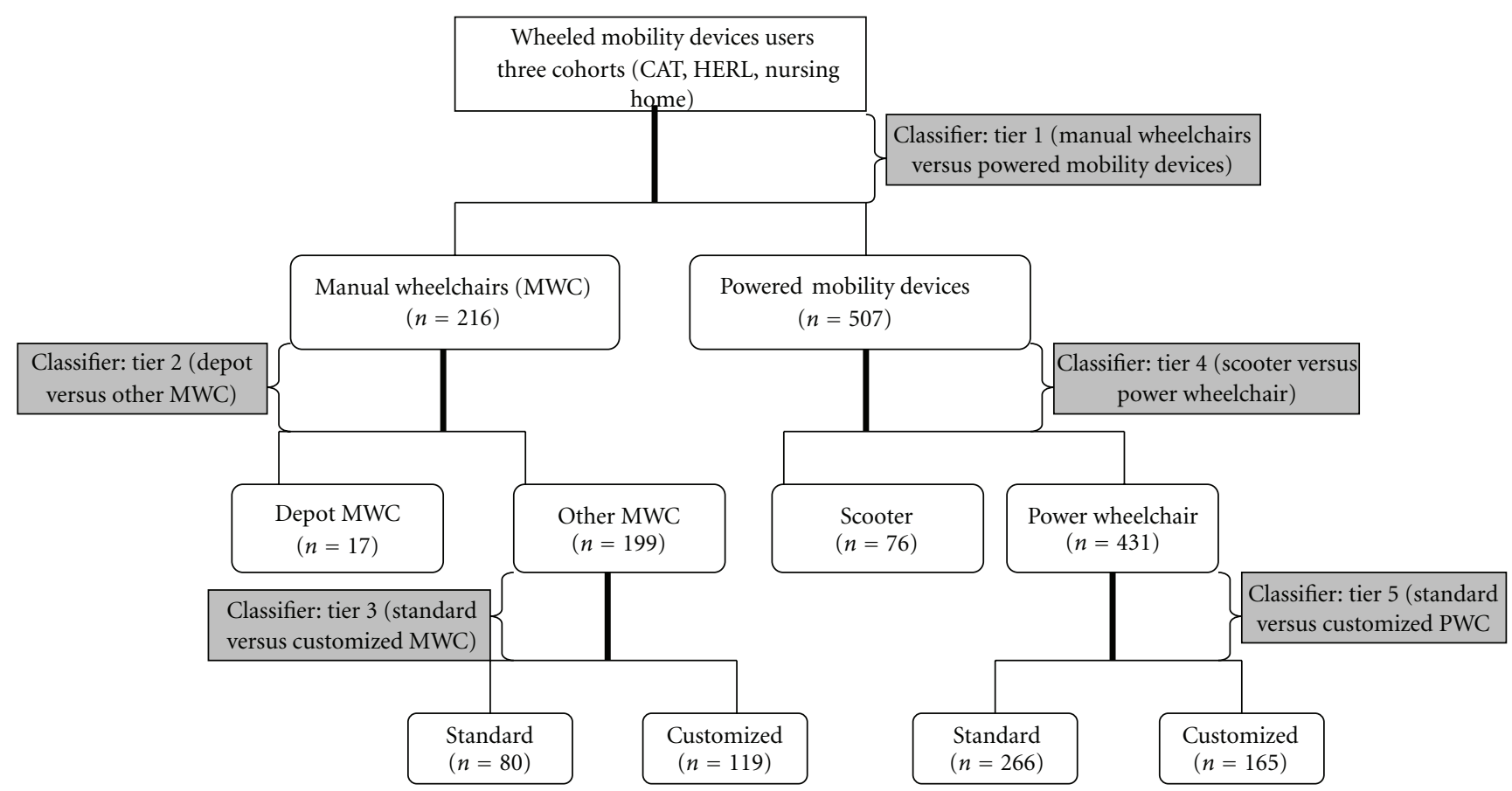

FIgURE 2: Data stratification chart.

to use standard power wheelchairs compared to customized power wheelchairs, while no difference was found for living setting $\left(\chi^{2}=0.33, P=.56\right)$ (Table 6$)$.

\section{Discussion}

This study examined what device was prescribed, but not necessarily the appropriateness of the WhMD currently in use. However, understanding factors that were associated to the selection and provision of one type of WhMD over others in all settings is the first step in the future development of guidelines for the prescription of WhMDs for older adults, much like the guidelines for the prescription of wheelchairs for the SCI population [15].

A significant difference may exist in the severity of medical conditions and the extent of functional limitations in those individuals using WhMDs, which could confound other associations or relationships. Hence, it is critical to use a stratification approach and to compare similar segments for identifying relationships. We used the classification approach of dividing the entire sample into different Tiers, and making comparisons of segments at each Tier for identifying factors that could have a significant impact on the use of one type of device over the others. Clinically, this method is valuable for WhMD provision in older adults since the broad question for this population is whether manual or powered devices were appropriately prescribed. For this study, we were only interested in using this analytical approach to detect differences in demographic and healthrelated factors among users of individual types of WhMDs.

For the Tier 1 classification, not living at home was the most significant factor associated with the use of manual wheelchairs. For our study, most of the individuals not living at home were living in a nursing home. The use of powered mobility devices is uncommon within nursing homes. This can be attributed to several reasons, one being the risk associated with driving powered mobility devices. Studies have demonstrated that many individuals within institutional settings do not receive power mobility devices because they were never referred for a proper, objective mobility device evaluation [21-23]. We also found that more females were using manual wheelchairs, and more males were using powered mobility devices. This issue needs to be explored with a larger and more diverse sample to determine whether this finding may be related to gender differences with respect to diagnoses that result in functional impairments which may make these devices more appropriate, or whether a true disparity in their provision exists. The diagnosis of a spinal cord condition was also found to be associated with the use of manual wheelchairs rather than powered mobility devices. Spinal cord conditions were not stratified into paraplegia versus tetraplegia, but the higher number of individuals with functional use of the upper limbs in this tier may explain why most were manual wheelchair users. Finally, age was found to be negatively associated with the use of powered mobility devices in our sample. Age alone should not be a determining factor as to whether an individual should receive a power mobility device. Rather, cognitive status and functional ability to operate the device are important considerations in the evaluation [24]. Indeed, a subsequent analysis indicated that higher age was associated with living in settings other than home, which, in turn, may indicate that cognitive status and functional ability were important in provision in this cohort. 
TABLe 1: Demographic characteristics of the sample.

\begin{tabular}{|c|c|}
\hline \multicolumn{2}{|l|}{ Total number of subjects $(N=723)$} \\
\hline Age (years) & $70.2 \pm 8.6$ \\
\hline \multicolumn{2}{|l|}{ Gender } \\
\hline Male & $401(56 \%)$ \\
\hline Female & $322(44 \%)$ \\
\hline \multicolumn{2}{|l|}{ Medical diagnosis $\S$} \\
\hline \multicolumn{2}{|l|}{ Neurological conditions $n=285(39 \%)$} \\
\hline $\begin{array}{l}\text { Cerebral vascular accident (hemiplegia, and } \\
\text { hemiparesis) }\end{array}$ & $86(30 \%)$ \\
\hline Multiple sclerosis & $73(26 \%)$ \\
\hline Movement disorders (Parkinson's and Ataxia) & $35(12 \%)$ \\
\hline Post-polio syndrome & $32(11 \%)$ \\
\hline Cerebral palsy & $22(8 \%)$ \\
\hline Other & $37(13 \%)$ \\
\hline \multicolumn{2}{|l|}{ Orthopedic conditions $n=140(19 \%)$} \\
\hline $\begin{array}{l}\text { Arthritis (osteoarthritis, rheumatoid } \\
\text { arthritis, fibromyalgia, and systemic lupus } \\
\text { erythematosus) }\end{array}$ & $82(58 \%)$ \\
\hline Amputation & $40(29 \%)$ \\
\hline Other & $16(11 \%)$ \\
\hline \multicolumn{2}{|l|}{ Spinal cord conditions $n=173(24 \%)$} \\
\hline Spinal cord injury & $144(82 \%)$ \\
\hline Other & $29(17 \%)$ \\
\hline \multicolumn{2}{|l|}{$\begin{array}{l}\text { Cardiovascular and pulmonary (CVP) } \\
\text { Conditions } n=73(10 \%)\end{array}$} \\
\hline Chronic obstructive pulmonary disease & $55(75 \%)$ \\
\hline Other & $18(25 \%)$ \\
\hline Other conditions $n=49(7 \%)$ & $49(100 \%)$ \\
\hline \multicolumn{2}{|l|}{ Living settings } \\
\hline Home & $576(80 \%)$ \\
\hline $\begin{array}{l}\text { Other (nursing homes, assisted living } \\
\text { centers, independent living centers) }\end{array}$ & $147(20 \%)$ \\
\hline
\end{tabular}

From the Tier 2 classification in our study, a negative association was found to exist between age and the use of lightweight or ultralightweight manual wheelchairs. Our results resemble those suggested by Hunt and colleagues, who also demonstrated greater likelihood of use of standard manual wheelchairs by older individuals as compared to their younger counterparts [15]. Our study also found that women were more likely to use depot style manual wheelchairs than men. Generally, although depot manual wheelchairs may be appealing because of their low cost, they are not appropriate for individuals who use a mobility device for extended periods of time or who require special seating requirements. Depot chairs, due to their weight and lack of customizability, should only be used for temporary transport of individuals on a short-term basis, such as through an airport or shopping mall. All of the 17 depot chairs in this study were used by individuals in nursing home settings and were not prescribed at the CAT or from the HERL registry. In nursing homes, it is common to see individuals receiving wheelchairs that are already available, such as when a fleet of depot wheelchairs is purchased for nursing home residents, rather than a customized solution based on their needs and requirements.

For the Tier 3 classification of the study, institutional living was found to have a negative association with the use of customizable manual wheelchairs. Within nursing home settings, residents are often provided with a standard rather than with a customizable manual wheelchair. Limited use by residents and the consideration of wheelchairs primarily as positioning devices, rather than mobility devices, influence this practice [10]. Although research shows the positive impact of provision of customizable wheelchairs on the level of functional performance and on the quality of life of the residents of institutional settings [25], not all individuals in these settings may use or receive these devices for several reasons. First, institutions may not recognize that devices should be custom fit to individual users, and even if an older adult receives a customized device, caregivers at these places may use the individually prescribed equipment for other residents. Second, although state programs known as the Home and Community Based Services (HCBS) program, or the Medicaid waiver program, are designed specifically to assist institutional settings (nursing homes) in acquiring specialized services including more expensive mobility devices for residents, [26] not all institutions are able or willing to send residents for a proper evaluation or to complete the necessary documentation to receive the devices. This has resulted in underutilization of that program in several states [26] and the use of inappropriate WhMDs by the older adults living in such settings.

Our study found that individuals with spinal cord conditions constituted the highest proportion of users of customizable manual wheelchairs, whereas individuals with other neurological conditions most frequently used standard manual wheelchairs. This is a cause for concern, especially since having certain progressive neurological conditions may warrant an individually customized device. No other research to date has focused on profiling the wheelchair users based on their medical diagnoses, which would be important in identifying the disparities and differences in the provision of different wheelchairs. The individuals with older age were also found to be using standard wheelchairs more often than customizable ones, which supports the findings from a previous study [15].

For the Tier 4 classification, individuals using scooters had a higher proportion of cardiovascular and pulmonary conditions, compared to those using power wheelchairs. Higher functional levels and the ability to transfer independently are required to use a scooter. Although this information was not available for our sample, it is possible that scooter users had higher functional levels, compared to those who used power wheelchairs, on the basis of their respective medical diagnoses. This hypothesis needs to be tested by comparing functional performance level and transfer ability between individuals using scooters versus power or manual wheelchairs. This study included very few individuals living in institutional settings who used scooters, which may be explained by the limited maneuverability 
TABle 2: Tier 1: Factors associated with use of manual versus powered mobility devices.

\begin{tabular}{|c|c|c|c|}
\hline & Manual wheelchair $(n=216)$ & Powered mobility devices $(n=507)$ & $P$-value \\
\hline Age $(y)$ & $71.8 \pm 9.5$ & $69.5 \pm 8.1$ & $.003^{*}$ \\
\hline \multicolumn{4}{|l|}{ Gender } \\
\hline Male & $157(73 \%)$ & $244(48 \%)$ & \multirow[b]{2}{*}{$<.001^{*}$} \\
\hline Female & $59(27 \%)$ & $263(52 \%)$ & \\
\hline \multicolumn{4}{|l|}{ Medical diagnosis } \\
\hline Neurological conditions & $86(40 \%)$ & $199(39 \%)$ & \multirow{5}{*}{$<.001^{*}$} \\
\hline Orthopedicconditions & $26(12 \%)$ & $114(22 \%)$ & \\
\hline Spinal cord conditions & $70(33 \%)$ & $103(20 \%)$ & \\
\hline CVP conditions & $14(7 \%)$ & $59(12 \%)$ & \\
\hline Other & $17(8 \%)$ & $32(6 \%)$ & \\
\hline \multicolumn{4}{|l|}{ Living Settings } \\
\hline Home & $122(56 \%)$ & $454(90 \%)$ & \multirow{2}{*}{$<.001^{*}$} \\
\hline Other & $94(44 \%)$ & $53(10 \%)$ & \\
\hline
\end{tabular}

* indicates a statistically significant difference or association.

TABLE 3: Tier 2: Factors associated with use of depot versus other manual wheelchairs.

\begin{tabular}{|c|c|c|c|}
\hline & Depot manual wheelchair $(n=17)$ & Other manual wheelchair $(n=199)$ & $P$-value \\
\hline Age $(y)$ & $77.5 \pm 9.9$ & $71.3 \pm 9.4$ & $.009 *$ \\
\hline \multicolumn{4}{|l|}{ Gender } \\
\hline Male & $8(47 \%)$ & $149(75 \%)$ & \multirow{2}{*}{$.01^{*}$} \\
\hline Female & $9(53 \%)$ & $50(25 \%)$ & \\
\hline \multicolumn{4}{|l|}{ Medical diagnosis } \\
\hline Neurological conditions & $5(31 \%)$ & $81(41 \%)$ & \multirow{5}{*}{$.05^{\dagger}$} \\
\hline Orthopedic conditions & $2(12 \%)$ & $24(12 \%)$ & \\
\hline Spinal cord conditions & $3(19 \%)$ & $67(34 \%)$ & \\
\hline CVP conditions & $4(25 \%)$ & $10(5 \%)$ & \\
\hline Other & $2(12 \%)$ & $15(8 \%)$ & \\
\hline \multicolumn{4}{|l|}{ Living settings } \\
\hline Home & $6(35 \%)$ & $116(58 \%)$ & \multirow{2}{*}{$.07^{\dagger}$} \\
\hline Other & $11(65 \%)$ & $83(42 \%)$ & \\
\hline
\end{tabular}

${ }^{*}$ indicates a statistically significant difference or association.

${ }^{\dagger}$ indicates a positive trend.

TABLE 4: Tier 3: Factors associated with use of standard versus customized manual wheelchairs.

\begin{tabular}{|c|c|c|c|}
\hline & Standard manual wheelchair $(n=80)$ & Customized manual wheelchair $(n=119)$ & $P$-value \\
\hline Age $(y)$ & $77.4 \pm 8.5$ & $67.1 \pm 7.5$ & $<.001^{*}$ \\
\hline \multicolumn{4}{|l|}{ Gender } \\
\hline Male & $51(64 \%)$ & $98(82 \%)$ & \multirow{2}{*}{$.003^{*}$} \\
\hline Female & $29(36 \%)$ & $21(18 \%)$ & \\
\hline \multicolumn{4}{|l|}{ Medical Diagnosis } \\
\hline Neurological conditions & $47(60 \%)$ & $34(29 \%)$ & \multirow{5}{*}{$<.001^{*}$} \\
\hline Orthopedic conditions & $10(13 \%)$ & $13(12 \%)$ & \\
\hline Spinal cord conditions & $4(5 \%)$ & $63(53 \%)$ & \\
\hline CVP conditions & $10(13 \%)$ & 0 & \\
\hline Other & $7(9 \%)$ & $8(7 \%)$ & \\
\hline \multicolumn{4}{|l|}{ Living settings } \\
\hline Home & $13(16 \%)$ & $103(87 \%)$ & \multirow{2}{*}{$<.001^{*}$} \\
\hline Other & $67(84 \%)$ & $16(13 \%)$ & \\
\hline
\end{tabular}

* indicates a statistically significant difference or association. 
TABLE 5: Tier 4: Factors associated with use of scooters versus power wheelchairs.

\begin{tabular}{lccc}
\hline & Scooter $(n=76)$ & Power wheelchair $(n=431)$ & $P$-value \\
\hline Age (y) & $69.5 \pm 8$ & $69.5 \pm 8.1$ & .98 \\
Gender & & & .92 \\
$\quad$ Male & $37(49 \%)$ & $207(48 \%)$ & \\
$\quad$ Female & $39(51 \%)$ & $224(52 \%)$ & $<.001^{*}$ \\
Medical diagnosis & & & \\
$\quad$ Neurological conditions & $24(32 \%)$ & $175(40 \%)$ & \\
Orthopedic conditions & $17(22 \%)$ & $97(22 \%)$ & $.04^{*}$ \\
Spinal cord conditions & $8(10 \%)$ & $95(22 \%)$ & $37(9 \%)$ \\
CVP conditions & $22(29 \%)$ & $27(6 \%)$ & \\
$\quad$ Other & $5(7 \%)$ & $381(88 \%)$ & \\
Living settings & & $50(12 \%)$ & \\
$\quad$ Home & $73(96 \%)$ & & \\
Other & $3(4 \%)$ & & \\
\hline
\end{tabular}

${ }^{*}$ indicates a statistically significant difference or association.

TABLE 6: Tier 5: Factors associated with use of standard (Group 1 and 2) versus customized (Group 3 and 4) power wheelchairs.

\begin{tabular}{|c|c|c|c|}
\hline & Standard power wheelchair $(n=266)$ & Customized power wheelchair $(n=165)$ & $P$-value \\
\hline Age (y) & $70.5 \pm 8.6$ & $67.8 \pm 7$ & $<.001^{*}$ \\
\hline \multicolumn{4}{|l|}{ Gender } \\
\hline Male & $107(40 \%)$ & $100(61 \%)$ & \multirow{2}{*}{$<.001^{*}$} \\
\hline Female & $159(60 \%)$ & $65(39 \%)$ & \\
\hline \multicolumn{4}{|l|}{ Medical diagnosis } \\
\hline Neurological conditions & $90(34 \%)$ & $85(52 \%)$ & \multirow{5}{*}{$<.001^{*}$} \\
\hline Orthopedic conditions & $79(30 \%)$ & $18(11 \%)$ & \\
\hline Spinal cord conditions & $46(17 \%)$ & $49(30 \%)$ & \\
\hline CVP conditions & $35(13 \%)$ & $2(1 \%)$ & \\
\hline Other & $16(6 \%)$ & $11(7 \%)$ & \\
\hline \multicolumn{4}{|l|}{ Living settings } \\
\hline Home & $237(89 \%)$ & $144(87 \%)$ & \multirow{2}{*}{.56} \\
\hline Other & $29(11 \%)$ & $21(13 \%)$ & \\
\hline
\end{tabular}

* indicates a statistically significant difference or association.

of scooters and the greater physical capacity required to operate them. Further, physical space is usually limited in institutional settings, and thus the accommodation of a scooter in such an environment may be problematic.

For the Tier 5 classification, our results indicated that higher proportions of individuals with neurological and spinal cord conditions were in the customized power wheelchair users group. In contrast, the standard power wheelchair user group had higher proportions of users with orthopedic or cardiovascular and pulmonary conditions. It is noteworthy that the need for customizable power wheelchairs was recognized for those with neurological diagnoses, but not their need for customizable manual wheelchairs. Our study also found that the older the age of the user of the WhMD, the greater the likelihood of using a standard power wheelchair rather than a customizable power wheelchair, similar to what has been pointed out in a previous study [15].

This study has some limitations. Some information related to the make and model of WhMD was missing from the registry data. Out of 321 registry participants who met the inclusion criterion of age $>60$ years for this study, we could only use complete data points for 280 participants. Therefore, 41 cases were excluded from the present study. A possibility of miscoding the raw data (data entry errors) prior to all analyses also exists. This, however, is one of the limitations of any secondary analysis study, which needs to be acknowledged. It is also important to acknowledge the statistical versus clinical significance approach used in the present study to interpret results. The small samples in some of the Tiers (such as the number of individuals using depot manual wheelchairs or scooters) may limit the external validity of the findings. The study did not take into account environmental and contextual factors, the preferences of the users, and the availability of resources such as health-care insurance, access to wheelchair, and seating clinics which are known to influence the types of WhMDs used. Finally, the study did not consider the number of health risks introduced by WhMDs, such as injuries related to wheelchair tips and falls, that may have resulted from a mismatch between an older person and an inappropriately prescribed or used 
WhMD. In the future, analyses of additional demographic environmental, and technological factors and their potential for interaction need to be conducted to better understand WhMD prescription and use by older adults. This study involved cursory analyses of data compiled from three sources. Future work should look at developing statistical models to predict the use of particular types of WhMDs by older adults, controlling their residential setting, their demographic profile, and their health characteristics.

\section{Conclusion}

Older adults who utilize WhMDs to enhance functional independence represent a diverse cohort. Their diversity lies in the differences that exist in their demographic characteristics, health-related factors, and living situations. Understanding these factors has tremendous value in matching types of WhMD to users' functional needs and requirements. The classification method implemented in our study could also assist clinicians in making appropriate decisions when prescribing WhMDs, whether manual or powered and standard or customized. This, in turn, will be helpful in defining the standard of care for the provision of WhMD for older adults.

\section{Author Disclosures}

This study was funded by the VA Center for Excellence in Wheelchairs and Associated Rehabilitation Engineering (Grant\# B3142C) and the National Science Foundation, Engineering Research Center on Quality of Life Technology (QoLT) (\#EEC 0540865). The contents of this paper do not represent the views of the Department of Veterans Affairs or the United States Government.

\section{References}

[1] Aging Statistics. Older American Update, Government Printing Office, Washington, DC, USA, 2006, Contract No.: Document Number.

[2] E. M. Agree, "The influence of personal care and assistive devices on the measurement of disability," Social Science and Medicine, vol. 48, no. 4, pp. 427-443, 1999.

[3] E. M. Agree, V. A. Freedman, J. C. Cornman, D. A. Wolf, and J. E. Marcotte, "Reconsidering substitution in long-term care: when does assistive technology take the place of personal care?" Journals of Gerontology-Series B Psychological Sciences and Social Sciences, vol. 60, no. 5, pp. S272-S280, 2005.

[4] L. M. Verbrugge, C. Rennert, and J. H. Madans, "The great efficacy of personal and equipment assistance in reducing disability," American Journal of Public Health, vol. 87, no. 3, pp. 384-392, 1997.

[5] H. Hoenig, D. H. Taylor Jr., and F. A. Sloan, "Does assistive technology substitute for personal assistance among the disabled elderly?" American Journal of Public Health, vol. 93, no. 2, pp. 330-337, 2003.

[6] D. H. Taylor and H. Hoenig, "The effect of equipment usage and residual task difficulty on use of personal assistance, days in bed, and nursing home placement," Journal of the American Geriatrics Society, vol. 52, no. 1, pp. 72-79, 2004.
[7] S. H. Kaye, T. Kang, and M. P. LaPlante, Wheelchair Use in the United States, University of California, San Francisco, Calif, USA, 2002, Contract No.: Document Number.

[8] L. G. Pawlson, M. Goodwin, and K. Keith, "Wheelchair use by ambulatory nursing home residents," Journal of the American Geriatrics Society, vol. 34, no. 12, pp. 860-864, 1986.

[9] P. Clarke and A. Colantonio, "Wheelchair use among community-dwelling older adults: prevalence and risk factors in a national sample," Canadian Journal on Aging, vol. 24, no. 2, pp. 191-198, 2005.

[10] D. A. Brechtelsbauer and A. Louie, "Wheelchair use among long-term care residents," Annals of Long-Term Care, vol. 7, no. 6, pp. 213-220, 1999.

[11] H. Hoenig, L. R. Landerman, K. M. Shipp, and L. George, "Activity restriction among wheelchair users," Journal of the American Geriatrics Society, vol. 51, no. 9, pp. 1244-1251, 2003.

[12] H. Hoenig, L. R. Landerman, K. M. Shipp et al., "A clinical trial of a rehabilitation expert clinician versus usual care for providing manual wheelchairs," Journal of the American Geriatrics Society, vol. 53, no. 10, pp. 1712-1720, 2005.

[13] H. Hoenig, C. Pieper, M. Zolkewitz, M. Schenkman, and L. G. Branch, "Wheelchair users are not necessarily wheelchair bound," Journal of the American Geriatrics Society, vol. 50, no. 4, pp. 645-654, 2002.

[14] S. Ganesh, A. Hayter, J. Kim, J. Sanford, S. Sprigle, and H. Hoenig, "Wheelchair use by veterans newly prescribed a manual wheelchair," Archives of Physical Medicine and Rehabilitation, vol. 88, no. 4, pp. 434-439, 2007.

[15] P. C. Hunt, M. L. Boninger, R. A. Cooper, R. D. Zafonte, S. G. Fitzgerald, and M. R. Schmeler, "Demographic and socioeconomic factors associated with disparity in wheelchair customizability among people with traumatic spinal cord injury," Archives of Physical Medicine and Rehabilitation, vol. 85, no. 11, pp. 1859-1864, 2004.

[16] S. L. Hubbard, S. G. Fitzgerald, D. M. Reker, M. L. Boninger, R. A. Cooper, and L. E. Kazis, "Demographic characteristics of veterans who received wheelchairs and scooters from Veterans Health Administration," Journal of Rehabilitation Research and Development, vol. 43, no. 7, pp. 831-844, 2006.

[17] L. Resnik and S. Allen, "Racial and ethnic differences in use of assistive devices for mobility: effect modification by age," Journal of Aging and Health, vol. 18, no. 1, pp. 106-124, 2006.

[18] J. C. Cornman and V. A. Freedman, "Racial and ethnic disparities in mobility device use in late life," Journals of Gerontology-Series B Psychological Sciences and Social Sciences, vol. 63, no. 1, pp. S34-S41, 2008.

[19] S. L. Hubbard, S. G. Fitzgerald, B. Vogel, D. M. Reker, R. A. Cooper, and M. L. Boninger, "Distribution and cost of wheelchairs and scooters provided by Veterans Health Administration," Journal of Rehabilitation Research and Development, vol. 44, no. 4, pp. 581-592, 2007.

[20] B. E. Dicianno and E. Tovey, "Power mobility device provision: understanding medicare guidelines and advocating for clients," Archives of Physical Medicine and Rehabilitation, vol. 88, no. 6, pp. 807-816, 2007.

[21] R. J. Mendoza, D. J. Pittenger, F. S. Savage, and C. S. Weinstein, "A protocol for assessment of risk in wheelchair driving within a healthcare facility," Disability and Rehabilitation, vol. 25, no. 10, pp. 520-526, 2003.

[22] W. B. Mortenson, W. C. Miller, J. Boily, B. Steele, E. M. Crawford, and G. Desharnais, "Overarching principles and 
salient findings for inclusion in guidelines for power mobility use within residential care facilities," Journal of Rehabilitation Research and Development, vol. 43, no. 2, pp. 199-208, 2006.

[23] W. B. Mortenson, W. C. Miller, J. Boily et al., "Perceptions of power mobility use and safety within residential facilities," Canadian Journal of Occupational Therapy, vol. 72, no. 3, pp. 142-152, 2005.

[24] Rehabilitation Engineering \& Assistive Technology Society of North America, Resna Position on the Application of Tilt, Recline, and Elevating Legrests for Wheelchairs, RESNA Press, Arlington, Va, USA, 2008, Contract No.: Document Number.

[25] E. Trefler, S. G. Fitzgerald, D. A. Hobson, T. Bursick, and R. Joseph, "Outcomes of wheelchair systems intervention with residents of long-term care facilities," Assistive Technology, vol. 16, no. 1, pp. 18-27, 2004.

[26] M. Kitchener, T. Ng, Y. L. Hyang, and C. Harrington, "Assistive technology in medicaid home- and community-based waiver programs," Gerontologist, vol. 48, no. 2, pp. 181-189, 2008. 


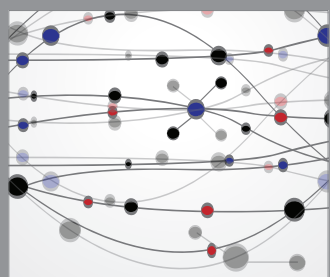

The Scientific World Journal
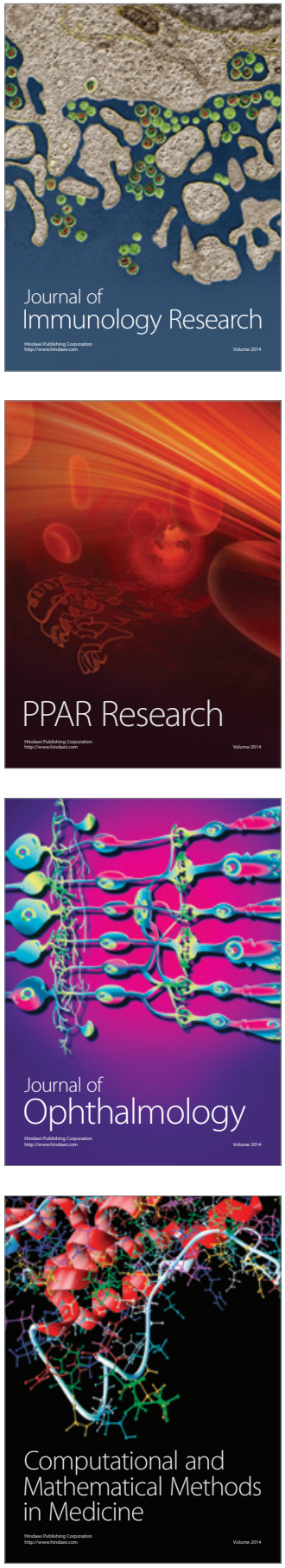

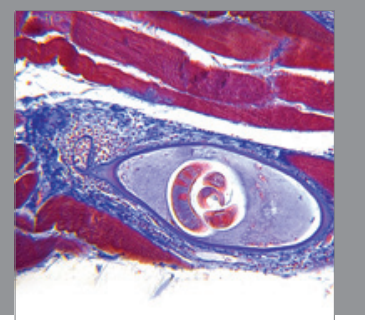

Gastroenterology

Research and Practice
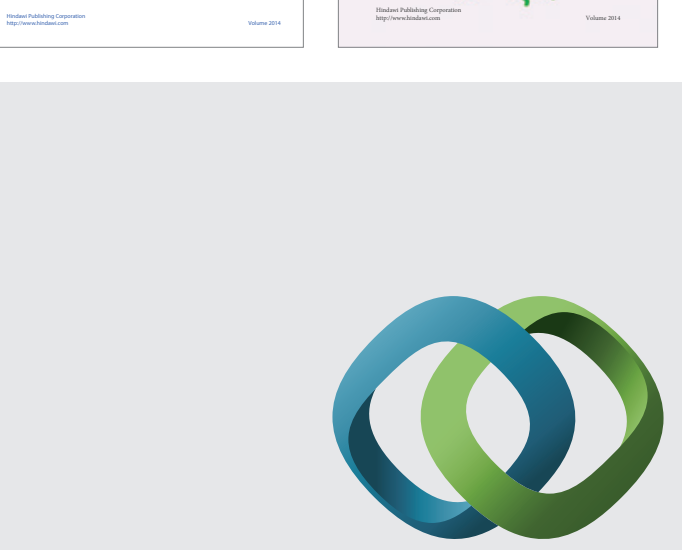

\section{Hindawi}

Submit your manuscripts at

http://www.hindawi.com
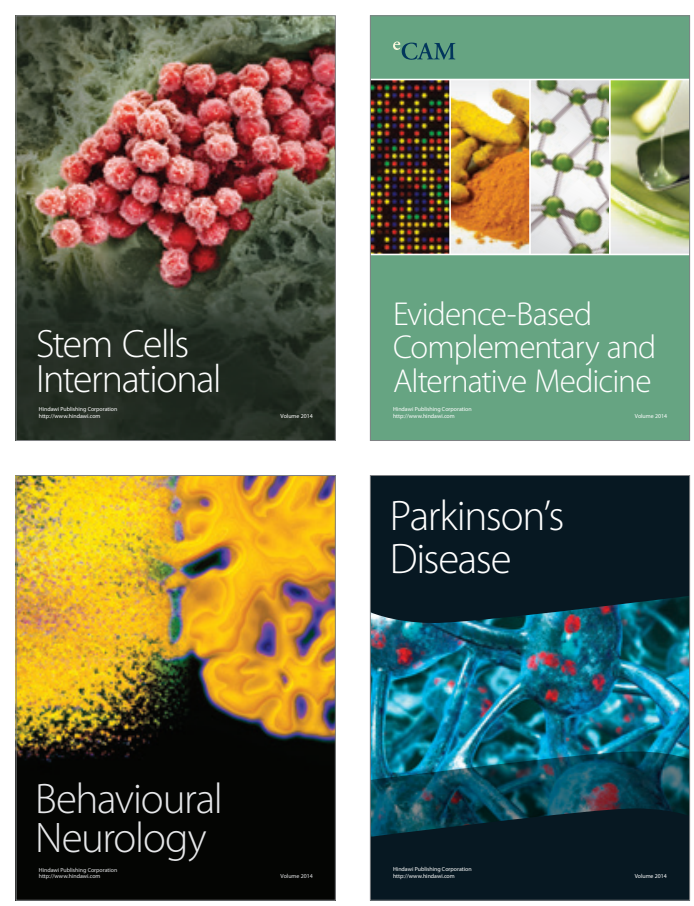

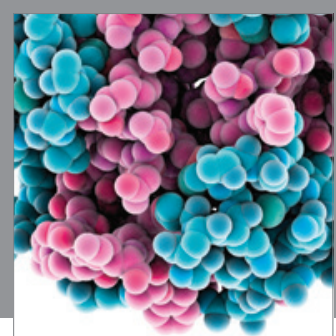

Journal of
Diabetes Research

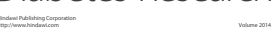

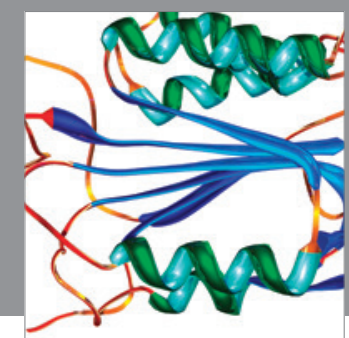

Disease Markers
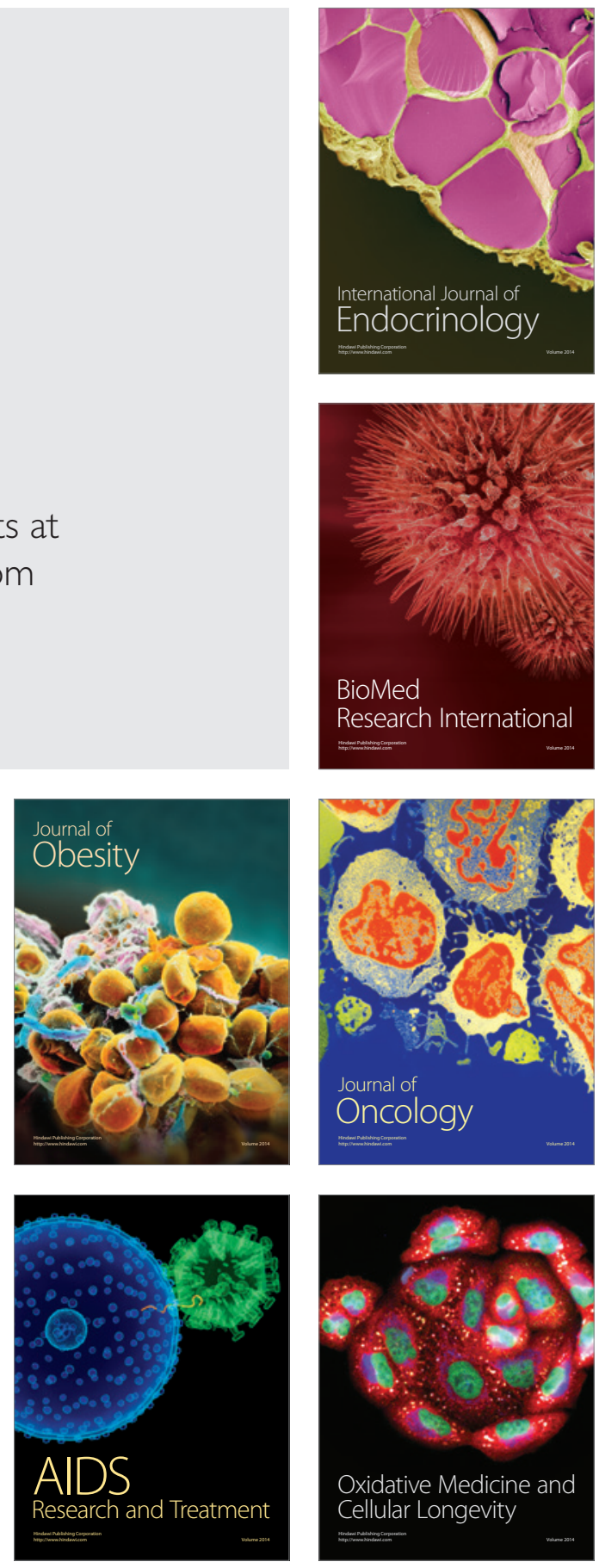